\title{
A New Machine Learning Algorithm to Optimize A Reduced Mechanism of 2-Butanone and the Comparison with Other Algorithms
}

\author{
Yunpeng Wang ${ }^{1,2 \#}$, Shibo Liu ${ }^{1 \#}$, Jia Cheng ${ }^{1}$, Xiao Wan ${ }^{1,2}$, Wentao Feng ${ }^{1,2}$, Nuo Yang ${ }^{1,2^{*}}$ and Chun Zou ${ }^{1^{*}}$
}

2-butanone (methyl ethyl ketone) has been identified as a potential alternative fuel and fuel tracer in recent studies. In this work, a reduced mechanism containing 50 species and 190 reactions for 2-butanone is developed for the first time. The raw reduced mechanism is built in three parts using decoupling methodology, a reduced $\mathrm{C}_{4}-\mathrm{C}_{\mathrm{n}}$ sub-mechanism, a reduced $\mathrm{C}_{2}-\mathrm{C}_{3}$ sub-mechanism and a detailed $\mathrm{H}_{2} / \mathrm{CO} / \mathrm{C}_{1}$ submechanism. Subsequently, the self-adaptive differential evolution algorithm of machine learning is proposed for optimizing the reaction rates of 31 reactions in the $\mathrm{C}_{4}-\mathrm{C}_{\mathrm{n}}$ sub-mechanism to predict the ignition delay times and laminar flame speeds in constant volume bombs. The optimized reduced mechanism is validated by the ignition delay times in shock tubes and laminar flame speeds in constant volume bombs. The results of the optimized reduced mechanism are similar to those of the detailed mechanism, which show it is reliable. Moreover, the performance of the self-adaptive differential evolution algorithm is much better than the genetic algorithm and the particle swarm optimization.

Keywords: 2-butanone; Alternative fuel; Self-adaptive differential evolution algorithm; Reduced mechanism

Received 19 November 2019, Accepted 23 December 2019

DOI: $10.30919 /$ esmm5f615

\section{Introduction}

The burning of fossil fuels has brought severe environmental problems all over the world. ${ }^{1,2}$ Considering the non-renewable of crude oil, biomass energy ${ }^{3}$ has been widely concerned as a clean and sustainable energy. Among numerous biofuel candidates, ${ }^{48}$ 2-butanone has been recently identified as a potential alternative fuel which can be used as an additive to replace ethanol in spark-ignition (SI) engines, especially for its excellent knock resistance $(\mathrm{RON}=117){ }^{9}$ In addition, 2-butanone also has the ability to be used as tracer material in engines laser diagnostic. ${ }^{10}$ For these combustion applications, it is vital important to understand the combustion kinetics of 2-butanone.

The detailed mechanism of 2-butanone was firstly developed by Decottignies et al., who used gas chromatography to measure a methane/air flame doped with 2-butanone. Serinyel et al. ${ }^{12}$ developed a detailed 2-butanone mechanism for high temperature by the measurement of the ignition delay times in shock tube. The measurement was performed at $T=1250-1850 \mathrm{~K}, P=1 \mathrm{~atm}, \varphi=0.5$ 2.0 and fuel concentrations in the range of $1.0 \%$ to $2.0 \%{ }^{13}$ Subsequently, Badra et al. ${ }^{14}$ updated the Serinyel's model by new measurement of the ignition delay times at $P=3,6.5 \mathrm{~atm}$ and $T=$ 1100-1500 K. Recently, Burke et al..$^{15}$ developed a new 2-butanone detailed chemical kinetic model (PCFC_v1) including both high and low temperature reaction pathways, based on quantum calculations. The

${ }^{I}$ State Key Laboratory of Coal Combustion, Huazhong University of Science and Technology, Wuhan 430074, China

${ }^{2}$ School of Energy and Power Engineering, Huazhong University of

Science and Technology, Wuhan 430074, China

*E-mail:nuo@hust.edu.cn; zouchun@hust.edu.cn

\# Y.W. and S.L. contributed equally to this work. model was validated against experimental data of laminar flame speeds, ignition delay times, flame speciation measurements and shock tube species-time profiles. Immediately after, Hemken et al. ${ }^{16}$ updated the model and proposed PCFC_v3 by adding new reaction classes of lowtemperature for three butanoyl radicals and improving the branch ratios between fuel radicals. As a result, the capabilities of PCFC_v3 prediction were improved for all the experiment measurement. Although the mechanism has been validated well, it contains 387 species and 2174 reactions, which is too large to be used in a CFD (Computational Fluid Dynamics) simulation. Therefore, a reduced mechanism of 2butanone is required for the engineering application. However, scarce works have studied the reduced mechanisms of 2-butanone.

Several methods have been proposed for the mechanism reduction. Traditional methods can be summarized as the direct reduction, ${ }^{17}, 18$ the directed relation graph with error propagation, ${ }^{19,}{ }^{20}$ chemical lumping ${ }^{21}$ and time-scale analysis. ${ }^{22}$ Obviously, all reduction methods need to remove some species and reactions in reduced mechanism. Therefore, in order to improve the prediction accuracy of the reduced mechanism, it is necessary to adjust the rate constants of some remaining reactions. In previous work, reaction rates adjustment was usually completed by manual operation, ${ }^{23}$ which is time-consuming and complicated. In recent years, many machine learning algorithms have been used to solve traditional problems. ${ }^{2430}$ For mechanisms reduction, a chaos genetic algorithm (CGA) proposed by Liu et al. ${ }^{31}$ was performed for the reaction rates adjustment of reduced mechanism. Chang et al. ${ }^{32}$ used the Non-dominated Sorting-based Genetic Algorithm and uncertainty quantification ${ }^{33}$ to develop an accurate reduced mechanism of n-pentanol. All of these algorithms belong to the class of evolution algorithms (EAs), in which the performance mainly depends on the combination of different generation strategies and control parameters. In order to get the most appropriate generation strategy and control parameters, it is generally needed to perform an exhaustive 
search, thus, resulting in a huge amount of computational costs, especially impossible for chemical kinetics calculation. Therefore, the effective and accurate algorithms for optimization are required. The selfadaptive differential evolution algorithm (SaDE) was developed by Suganthan et al., ${ }^{34}$ in which both generation strategy and control parameters are adaptive adjustment during evolution. Consequently, the more suitable generation strategy and control parameters can be determined automatically at different phases of evolution process.

In the present work, the 2-butanone raw reduced mechanism containing 50 species and 190 reactions is built in three parts, ${ }^{35} \mathrm{a}$ reduced $\mathrm{C}_{4}-\mathrm{C}_{\mathrm{n}}$ sub-mechanism, a reduced $\mathrm{C}_{2}-\mathrm{C}_{3}$ sub-mechanism and a detailed $\mathrm{H}_{2} / \mathrm{CO} / \mathrm{C}_{1}$ sub-mechanism. Subsequently, the self-adaptive differential evolution algorithm $(\mathrm{SaDE})^{34}$ is employed to optimize the reaction rate constants automatically due to its fast convergent speed and convenient operability. The ignition delay times in shock tube and laminar flame speeds are used for the validation of the reduced mechanism. Finally, the performance of $\mathrm{SaDE}$ algorithm is compared with genetic algorithm and particle swarm optimization.

\section{Methodology}

\subsection{The SaDE algorithm}

Fig. 1 is the data flow diagram of $\mathrm{SaDE}$ algorithm. The main process of $\mathrm{SaDE}$, similar to other evolutionary algorithms (Eas), is aimed to find better fitness value (minimization task usually) through the iteration of the population. ${ }^{36}$ The population is updated by genetic operators of mutation, crossover and selection like Darwinian evolution. The initial population was generated by coding genes in domain of definition randomly and a fitness function is set as the evolution index. Then genetic operators (mutation and crossover) will be performed on present population to generate new individuals. Subsequently, the greedy selection strategy, which means a new individual will be passed if and only if it has a better fitness value, is used to choose the final individual for next generation. Obviously, the update of the mutation strategy and control parameters self-adaptation in crossover are crucial steps of $\mathrm{SaDE}$ algorithm and presented as follow:

1) The update of the mutation strategy

The mutation strategy pool for present work consist of four different strategies, i,e. "DE/rand/1/bin", "DE/rand-to-best/2/bin", "DE/rand/2/bin", "DE/current-to-rand/1". They are effective and famous mutation strategies in DE algorithm and the name means the generation rule of mutation individual. A mutation strategy is selected to generate new mutant individual according to the success probability learned from previous generations. ${ }^{34}$ The success probability is calculated by the following equation,

$$
P_{k, G}=\frac{S_{k, G}}{\sum_{k=1}^{K} S_{k, G}}
$$

where

$$
S_{k, G}=\frac{\sum_{g=G-L P}^{G-1} n s_{k, g}}{\sum_{g=G-L P}^{G-1} n s_{f, g}+\sum_{g=G-L P}^{G-1} n f_{k, g}}+\epsilon
$$

$$
(k=1,2 \ldots ., K ; G>L P)
$$

$S_{k, G}$ represents the selection probability of strategy $k$ in generation $G$. $L P$ is the learning period during evolution process. $n s_{k, g}$ is the number of individuals generated by the $k$ strategy, which successfully passing the greedy selection within the previous $L P$ generations. $n s_{f, g}$ is the number of failed individuals. Moreover, a small constant value $\in=$ 0.01 is assigned to avoid the potential null values.

2) Parameter self-adaptation

$\mathrm{SaDE}$ algorithm has three crucial control parameters, $i$, e. population size $N P$, scaling factor $F$, and crossover rate $C R$. NP is suggested no less than 5 times of genes. ${ }^{34} F$ and $C R$ are defined as followed:

$$
\begin{aligned}
F & =N(0.5,0.3) \\
C R & =N(C R m, 0.1)
\end{aligned}
$$

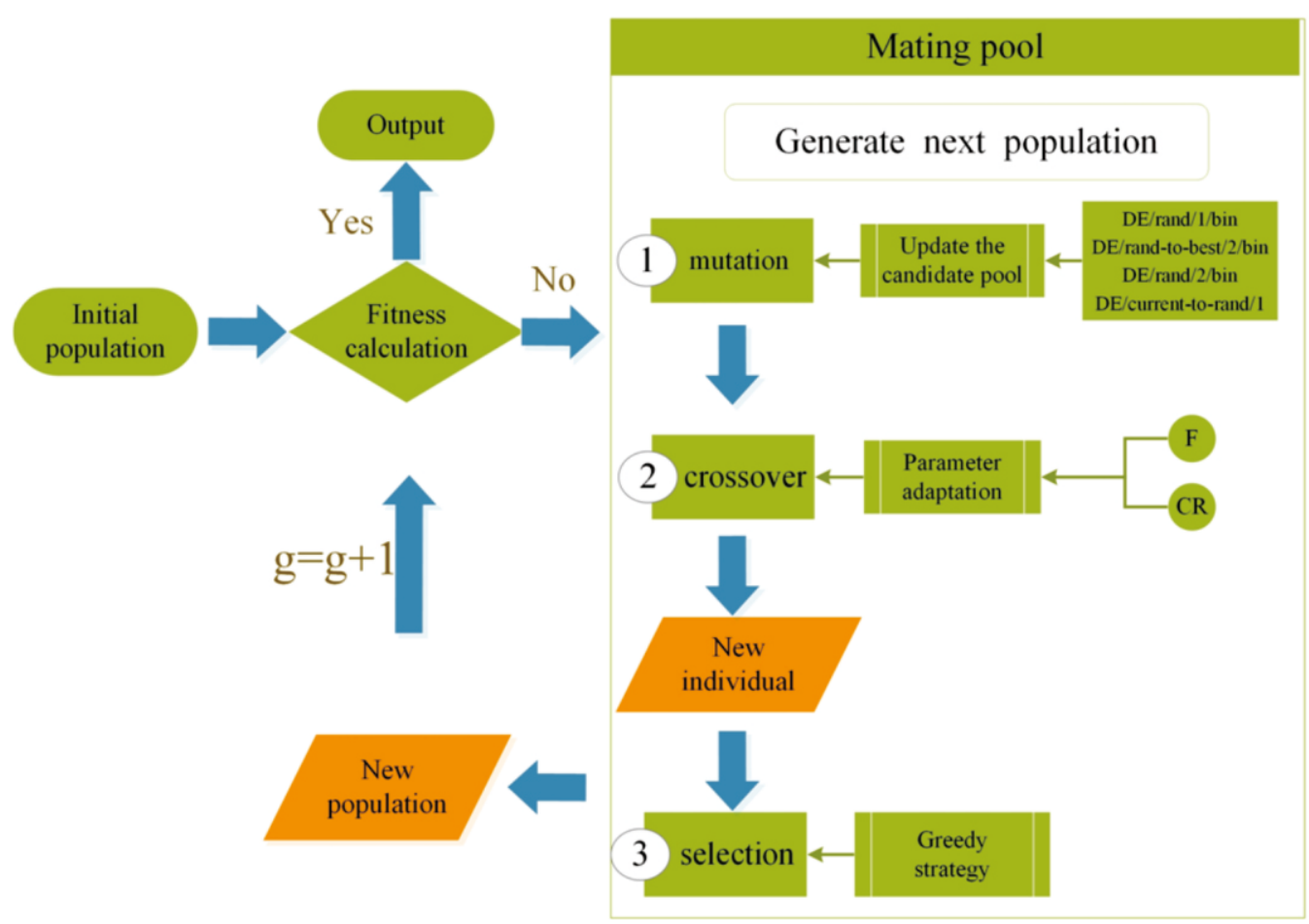

Fig. 1 The data flow diagram of SaDE algorithm. 
where $N$ means a normal distribution, $C R m$ is the mean value of $C R$ learned from previous $L P$ generations and $C R m$ is initialized as 0.5 .

As demonstrated by a large number of numeric simulation experiments in, ${ }^{37}$ the choice of strategy will make a great difference when solving different optimization problems. For specific problems with different characteristics, the value of $C R$ and $F$ has a significant impact on algorithm performance, especially for the convergence speed. By dynamically adjusting the generation strategy and control parameters, the SaDE algorithm can maintain both exploitation and exploration ability throughout the entire evolution process. According to the accurate results on various test functions ${ }^{34}$ and the process of automatic regulation, it is concluded that $\mathrm{SaDE}$ algorithm possesses robust performance to handle optimization problems with distinct properties.

2.2 Simulation of the ignition delay time and laminar flame speed. The ignition delay time was simulated using a zero-dimensional model with constrained volume and adiabatic boundary in Cantera 2.4.0. ${ }^{38}$

The laminar flame speed was defined as the propagation speed of a steady, laminar, one-dimensional, planar, adiabatic flame. ${ }^{39}$ In the present work, it was simulated using the freely-propagating, premixed flame model in Cantera 2.4.0. ${ }^{38}$ The soret effect was accounted for and the multi-component transport model was applied. The grid ratio was set to 3 , the slope 0.07 and the curve 0.14 to make sure the results are independent of the grid.

\subsection{Genetic algorithm and particle swarm optimization}

As mentioned above, many evolutionary algorithms (EAs) have been proposed for global optimization problem. In the present study, in order to further estimate the performance of $\mathrm{SaDE}$, two famous evolutionary algorithms, genetic algorithm $(\mathrm{GA})^{40}$ and particle swarm optimization (PSO), ${ }^{41}$ are also conducted for 2-butanone reduced mechanism optimization.

The typical genetic algorithm encodes the potential solutions by genes for a specific problem, and uses genetic operators to evolve these genes to get the convergent solution. Crossover rate is the crucial control parameter involved in GA. The algorithm is expected to converge fast with a small $\mathrm{CR}$ value and express a better exploration power with a large $\mathrm{CR}$ value. ${ }^{42}$

Particle swarm optimization is inspired by the social species in nature, like bird, ant and fish. It is initialized with a population of random solutions and each potential solution is assigned a randomized velocity. Then, the potential solutions, named particles, will search through the domain for best solution as a fish school searching for food. Obviously, a large velocity can search solution domain fast but may miss the best solution. A small velocity, which mean a high resolution ratio, can search the solution more carefully while the rate of convergence is slow. ${ }^{43}$

\section{Mechanism construction}

In this study, the 2-butanone raw reduced mechanism is built using the decoupling method. ${ }^{446}$ The main step to build a reduced mechanism is as follow:

First of all, based on the path analysis of the PCFC-v $3,{ }^{47}$ the main reaction pathways during the combustion of 2-butanone are identified. Secondly, the isomers of large molecules or radicals are represented by only one empirical formula. For example, $\mathrm{C}_{4} \mathrm{H}_{7} \mathrm{O}$ represents for $\mathrm{CH}_{3} \mathrm{CHCOCH}_{3}, \mathrm{CH}_{2} \mathrm{CH}_{2} \mathrm{COCH}_{3}$ and $\mathrm{CH}_{3} \mathrm{CH}_{2} \mathrm{COCH}_{2}$, which are $\mathrm{H}-$ abstraction products of butanone. Only the thermal and transport properties of $\mathrm{CH}_{3} \mathrm{CHCOCH}_{3}$ will be adopted due to its lowest bond dissociation energy. As a result, the amount of 2-butanone H-abstraction reactions can be greatly reduced from 39 in PCFC-v3 to only 3 in the reduced mechanism. The major reaction pathway related to fuel molecule was then developed in this way and shown in Fig. 2. The

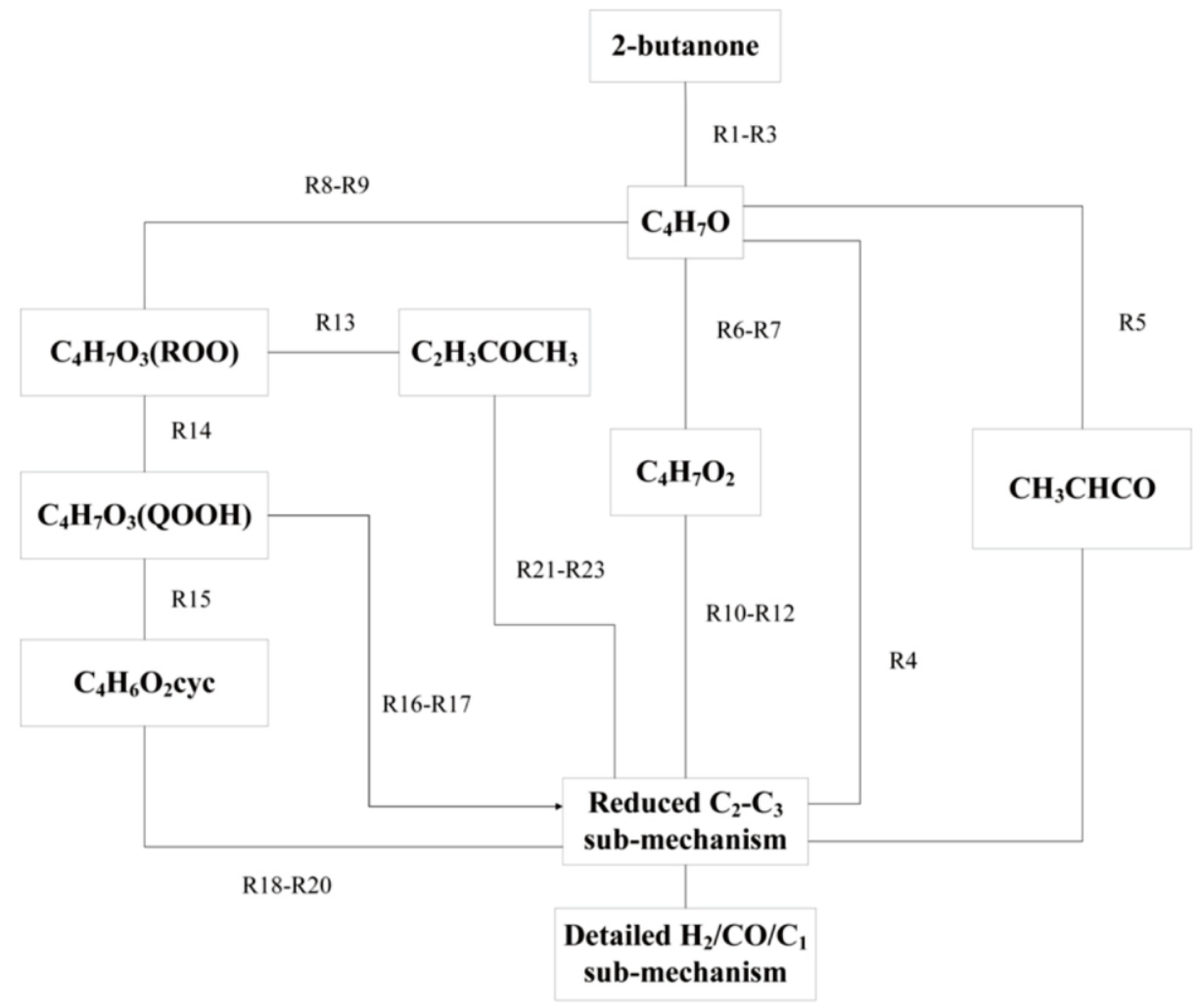

Fig. 2 Major reaction paths of reduced 2-butanone mechanism. 
reduced $\mathrm{C}_{4}-\mathrm{C}_{\mathrm{n}}$ sub-mechanism still includes the high-temperature, the low-temperature and the functional group reactions.

The reduced $\mathrm{C}_{2}-\mathrm{C}_{3}$ mechanism is mainly taken from ${ }^{32}$ due to its good performance. Further, several reactions involving $\mathrm{CH}_{3} \mathrm{CHO}$ and $\mathrm{CH}_{3} \mathrm{CHCO}$, which are important intermediates during the oxidation of 2-butanone, are integrated into the reduced $\mathrm{C}_{2}-\mathrm{C}_{3}$ mechanism.

The detailed $\mathrm{H}_{2} / \mathrm{CO} / \mathrm{C}_{1}$ sub-mechanism is taken from ${ }^{48,49}$ due to its accuracy in predicting ignition delay time, JSR species measurement, flow reactor species measurement and laminar flame speed.

By combining the reduced $\mathrm{C}_{4}-\mathrm{C}_{\mathrm{n}}$ sub-mechanism, the reduced $\mathrm{C}_{2}-$ $\mathrm{C}_{3}$ sub-mechanism and the detailed $\mathrm{H}_{2} / \mathrm{CO} / \mathrm{C}_{1}$ sub-mechanism, a 2butanone raw reduced mechanism with 50 species and 190 reactions is constructed.

\section{Mechanism optimization}

In the raw-reduced mechanism built above, the reaction rates of $\mathrm{C}_{4}-\mathrm{C}_{\mathrm{n}}$ sub-mechanism are taken from the detailed mechanism PCFC_v3 developed by Burke et al ${ }^{15,47}$ The results calculated by the raw-reduced mechanism is shown in Fig. 3. It can be seen that the predicted results of raw-reduced mechanism are extremely bad among all conditions. Thus, it is necessary to tune the reaction rates of $\mathrm{C}_{4}-\mathrm{C}_{\mathrm{n}}$ sub-mechanism to improve the performance.

\subsection{Optimization setting}

In the present study, the reaction rates adjustment was performed by SaDE algorithm. ${ }^{34}$ Each individual represents a potential reduced mechanism of 2-butanone, and the genes in individual are reaction rates of 31 reactions in the $\mathrm{C}_{4}-\mathrm{C}_{\mathrm{n}}$ sub-mechanism, which are listed in Table 2. The population consists of 200 individuals (no less than 5 times of genes) and the individual consists of 37 genes (2 multiplicative factors of pre-exponential factors for the pressure-dependent reactions including R4, R21, R26, R27, R28 and R29).

The fitness function is defined as follows:

$$
f\left(x_{i, g}\right)=\frac{1}{N} \sum_{n=1}^{N} \frac{\tau_{k}-\tau_{0}}{\tau_{0}}
$$

where $f\left(x_{i, q}\right)$ is the fitness value of $i$-th individual in the generation $g ; N$ is the number of different experimental conditions; $\tau_{k}$ and $\tau_{0}$ represent the simulated and experimental data, respectively.

Moreover, a terminal condition shown in Eq. (6) is introduced to improve the convergence of the optimization progress.

$$
\text { Terminal condition }=\left\{\begin{array}{c}
f_{\text {avg,g-30 }}-f_{\text {avg,g }} \leq 1 \mathrm{e}-2 \\
f_{\text {min }, g-30}==f_{\text {ming }}
\end{array}\right.
$$

where $f_{\text {min. }}$ and $f_{\text {min. } .30}$ represent the minimum fitness value of generation $g$ and generation $g$-30, respectively. In other words, the best optimized reduced mechanism of generation $g$ and generation $g$-30. Once the termination condition is met, the best individual of generation $g$ is obtained as the final convergent solution, and the optimized reduced mechanism.

The main steps for optimizing raw-reduced mechanism shown in Fig. 4 can be expressed as follows:

1) The initial population was generated randomly by assigning value to individuals within the domain of genes.

2) The ignition delay times and laminar flame speeds at all conditions are calculated using Cantera code. ${ }^{38}$ Then, the fitness value of each individual is calculated.

3) The terminal condition is judged. If yes, the final convergent solution is output, otherwise, the update of mutation strategy and
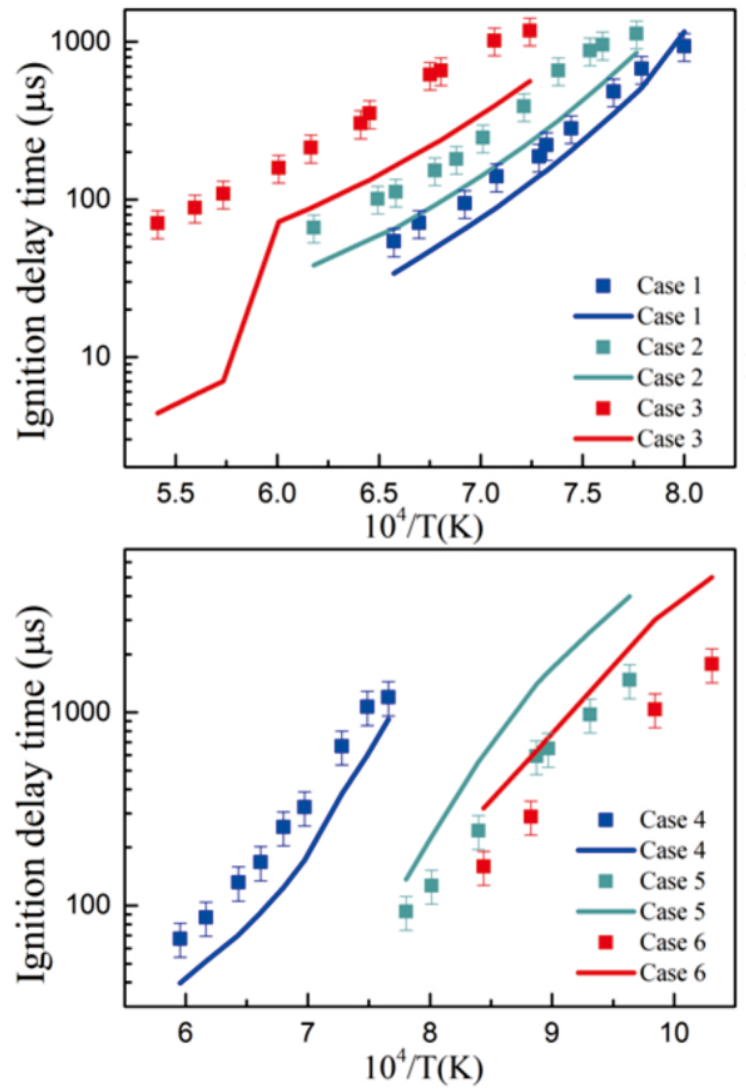
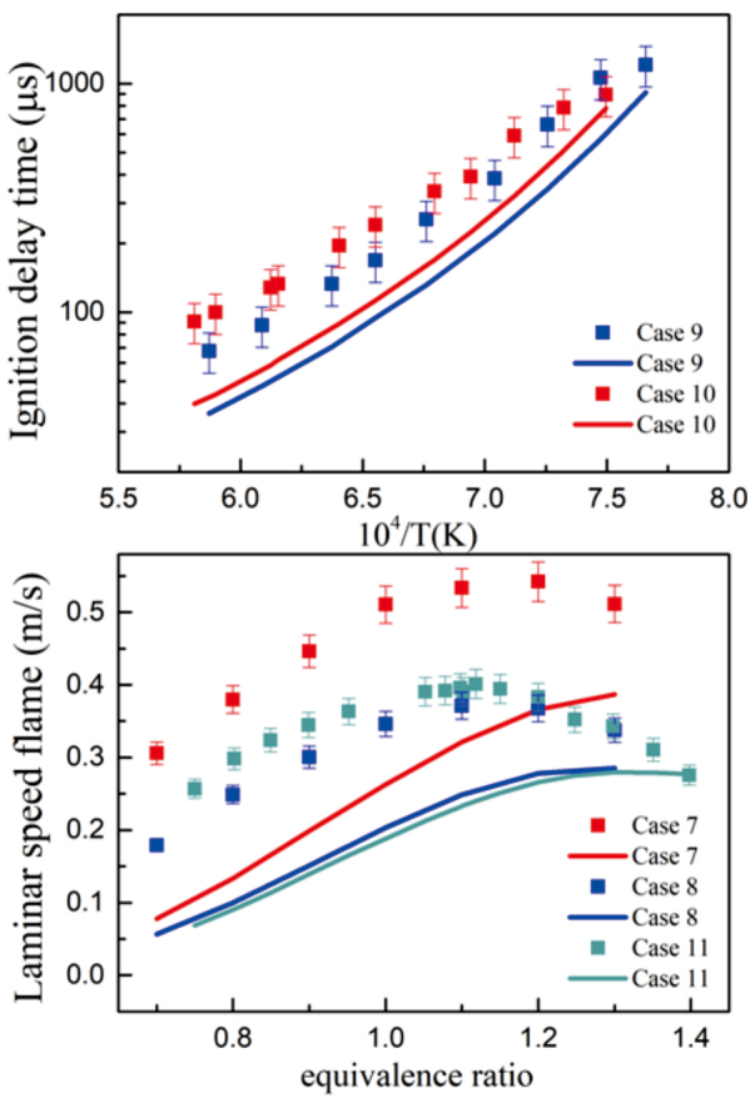

Fig. 3 Simulated results of raw-reduced mechanism. Dots represent experimental data, solid lines represent the simulated data. 
parameter adaption are conducted by learning from previous $L P$ generations.

4) The new generation is generated by using the operator of mutation, crossover and selection in the mating pool.

5) Steps 2) - 4) are repeated until the terminal condition is met.

\subsection{Optimization object}

For the optimization of the reduced mechanism, the ignition delay times measured by Serinyel et al. ${ }^{12}$ at $T=1250-1850 \mathrm{~K}, P=1$ bar, $\varphi=0.5$ 2.0, Burke et al. ${ }^{15}$ at $T=960-1300 \mathrm{~K}, P=20$ and 40 bar, $\varphi=1.0$ and laminar flame speeds measured by Burke et al. ${ }^{15}$ at $T=373 \mathrm{~K}, P=1$ bar and 5 bar, $\varphi=0.7-1.3$, are set as the training dataset (Cases 1-8) for optimization process. Moreover, to further validate the reliability of reduced mechanism, the ignition delay times measured by Serinyel et $a l .{ }^{12}$ at $T=1250-1850 \mathrm{~K}, P=1 \mathrm{bar}, \varphi=1.5$ and 2.0 and laminar flame speeds measured by Serinyel et al. ${ }^{50}$ at $T=305 \mathrm{~K}, P=1 \mathrm{~atm}, \varphi=0.7$ 1.4, are set as the test dataset (Cases 9-11) for final validation. Table 1 lists the conditions and mixture compositions, in which $\varphi$ is the equivalence ratio.

\subsection{Optimization results}

The evolution of the fitness function is shown in Fig. 5. As can be seen from Fig. 5, the terminal condition is met at 173th generation. Thus, the best individual in 173th generation is obtained as the final convergent solution. The result of optimized reaction rates is listed in Table 2.

\subsection{Evaluation indicators of mechanism}

Mechanism results are evaluated through two indicators, including mean absolute error (MAE) and mean absolute percentage error (MAPE), which are defined as follows:

$$
\begin{gathered}
\text { MAE }=\frac{1}{n} \sum_{i=1}^{n}\left|f_{i}-y_{i}\right| \\
\text { MAPE }=\frac{1}{n} \sum_{i=1}^{n}\left|\frac{f_{i}-y_{i}}{y_{i}}\right| \times 100 \%
\end{gathered}
$$

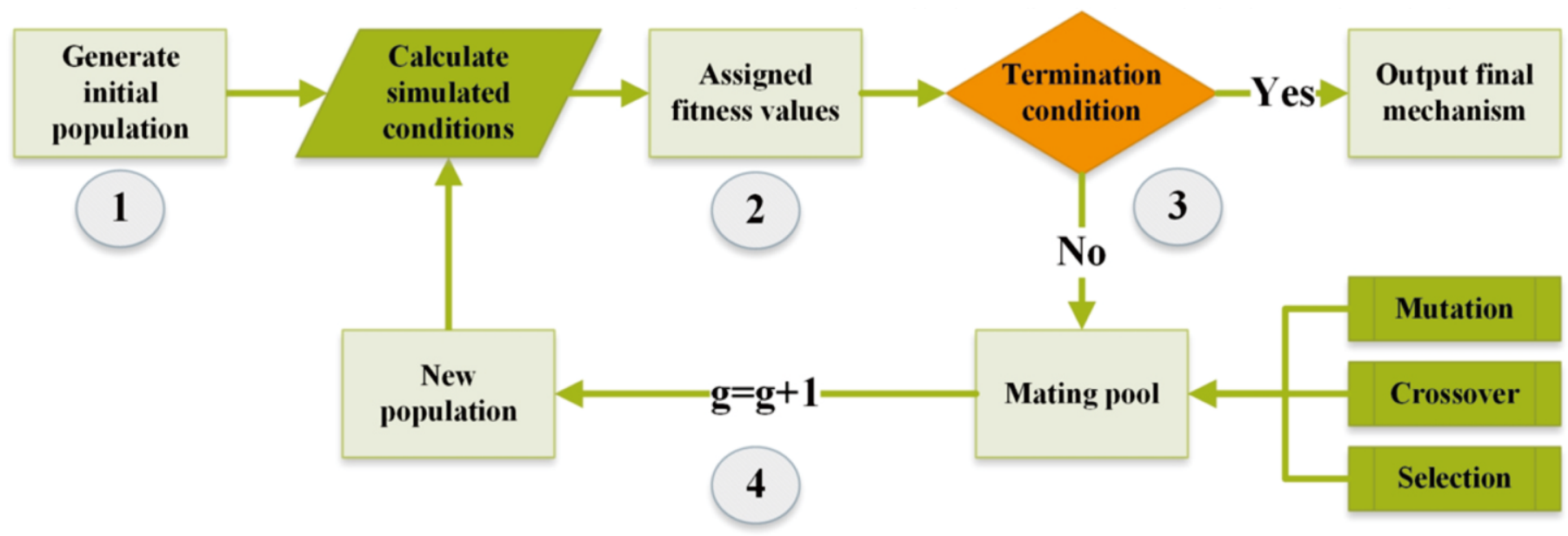

Fig. 4 The implementation process of reaction rates adjustment by SaDE algorithm.

\begin{tabular}{|c|c|c|c|c|c|c|c|}
\hline & & Case & Pressure & $\varphi$ & 2-butano ne $(\%)$ & $\mathrm{O}_{2}(\%)$ & $\operatorname{Ar}(\%)$ \\
\hline \multirow{10}{*}{$\begin{array}{c}\text { Training } \\
\text { set }\end{array}$} & \multirow{6}{*}{$\begin{array}{c}\text { Ignition delay } \\
\text { times }\end{array}$} & 1 & $1 \mathrm{~atm}$ & 0.5 & 1 & 11 & 88 \\
\hline & & 2 & $1 \mathrm{~atm}$ & 1 & 1 & 5.5 & 93.5 \\
\hline & & 3 & $1 \mathrm{~atm}$ & 2 & 1 & 2.75 & 96.25 \\
\hline & & 4 & $1 \mathrm{~atm}$ & 1.25 & 1.25 & 5.0 & 93.75 \\
\hline & & 5 & 20 bar & 1 & 1 & 5.5 & 93.5 \\
\hline & & 6 & 40 bar & 1 & 1 & 5.5 & 93.5 \\
\hline & & Case & Pressure & $\mathrm{T}(\mathrm{K})$ & $\varphi$ & $\mathrm{O}_{2}(\%)$ & $\mathrm{N}_{2}(\%)$ \\
\hline & Laminar & 7 & 5 bar & 373 & $0.7 \sim 1.3$ & 5.5 & 20.68 \\
\hline & flame speeds & 8 & $1 \mathrm{bar}$ & 373 & $0.7 \sim 1.3$ & 5.5 & 20.68 \\
\hline & & Case & Pressure & $\varphi$ & 2-butanone (\%) & $\mathrm{O}_{2}(\%)$ & $\operatorname{Ar}(\%)$ \\
\hline \multirow{4}{*}{ Test set } & Ignition delay & 9 & $1 \mathrm{~atm}$ & 1.5 & 1.5 & 5.5 & 93 \\
\hline & times & 10 & $1 \mathrm{~atm}$ & 2.0 & 2.0 & 5.5 & 92.5 \\
\hline & & Case & Pressure & $\mathrm{T}(\mathrm{K})$ & $\varphi$ & $\mathrm{O}_{2}(\%)$ & $\mathrm{N}_{2}(\%)$ \\
\hline & $\begin{array}{c}\text { Laminar } \\
\text { flame speeds }\end{array}$ & 11 & $1 \mathrm{~atm}$ & 305 & $0.7-1.4$ & 5.5 & 20.68 \\
\hline
\end{tabular}

Table 1 Conditions and mixture compositions in the present study. 
Table 2 Arrhenius rate constants adjustment results.

\begin{tabular}{|c|c|c|c|}
\hline \multirow{2}{*}{$\begin{array}{c}\text { Reaction } \\
\text { NO. }\end{array}$} & \multirow[b]{2}{*}{ Reactions } & \multicolumn{2}{|c|}{ Arrhenius rate constants } \\
\hline & & $\begin{array}{l}\text { Raw-reduced } \\
\text { mechanism }\end{array}$ & $\begin{array}{l}\text { Optimized reduced } \\
\text { mechanism }\end{array}$ \\
\hline $\mathrm{R} 1$ & $\mathrm{C}_{2} \mathrm{H}_{5} \mathrm{COCH}_{3}+\mathrm{OH} \Leftrightarrow \mathrm{C}_{4} \mathrm{H}_{7} \mathrm{O}+\mathrm{H}_{2} \mathrm{O}$ & $2.36 \mathrm{e}+02$ & $3.72 \mathrm{e}+01$ \\
\hline $\mathrm{R} 2$ & $\mathrm{C}_{2} \mathrm{H}_{5} \mathrm{COCH}_{3}+\mathrm{H} \Leftrightarrow \mathrm{C}_{4} \mathrm{H}_{7} \mathrm{O}+\mathrm{H}_{2}$ & $1.99 \mathrm{e}+06$ & $3.37 \mathrm{e}+06$ \\
\hline R3 & $\mathrm{C}_{2} \mathrm{H}_{5} \mathrm{COCH}_{3}+\mathrm{CH}_{3} \mathrm{O}_{2}<\mathrm{C}_{4} \mathrm{H}_{7} \mathrm{O}+\mathrm{CH}_{3} \mathrm{O}_{2} \mathrm{H}$ & $1.87 \mathrm{e}-03$ & $4.99 \mathrm{e}-02$ \\
\hline \multirow{2}{*}{ R4 } & $\mathrm{C}_{2} \mathrm{H}_{5} \mathrm{COCH}_{3}(+\mathrm{M}) \Leftrightarrow \mathrm{C}_{2} \mathrm{H}_{5}+\mathrm{CH}_{3} \mathrm{CO}(+\mathrm{M})$ & $3.58 \mathrm{e}+27$ & $2.74 \mathrm{e}+28$ \\
\hline & Low-pressure limit & $2.58 \mathrm{e}+79$ & $8.24 \mathrm{e}+77$ \\
\hline R5 & $\mathrm{C}_{4} \mathrm{H}_{7} \mathrm{O} \Leftrightarrow \mathrm{CH}_{3}+\mathrm{CH}_{3} \mathrm{CHCO}$ & $1.56 \mathrm{e}+20$ & $7.40 \mathrm{e}+21$ \\
\hline R6 & $\mathrm{C}_{4} \mathrm{H}_{7} \mathrm{O}+\mathrm{HO}_{2} \Leftrightarrow=\mathrm{RO}+\mathrm{OH}$ & $1.76 \mathrm{e}+29$ & $1.90 \mathrm{e}+30$ \\
\hline R7 & $\mathrm{C}_{4} \mathrm{H}_{7} \mathrm{O}+\mathrm{CH}_{3} \mathrm{O}_{2}<=>\mathrm{RO}+\mathrm{CH}_{3} \mathrm{O}$ & $2.51 \mathrm{e}+25$ & $5.02 \mathrm{e}+26$ \\
\hline $\mathrm{R} 8$ & $\mathrm{C}_{4} \mathrm{H}_{7} \mathrm{O}+\mathrm{O}_{2}<>\mathrm{ROO}$ & $5.82 \mathrm{e}+60$ & $7.24 \mathrm{e}+61$ \\
\hline R9 & $\mathrm{C}_{4} \mathrm{H}_{7} \mathrm{O}+\mathrm{O}_{2}<>\mathrm{ROO}$ & $1.17 \mathrm{e}+107$ & $1.57 \mathrm{e}+108$ \\
\hline R10 & $\mathrm{RO}<=>\mathrm{CH}_{3} \mathrm{CO}+\mathrm{CH}_{3} \mathrm{CHO}$ & $8.68 \mathrm{e}+10$ & $1.91 \mathrm{e}+12$ \\
\hline R11 & $\mathrm{RO}<=>\mathrm{CH}_{2} \mathrm{O}+\mathrm{C}_{2} \mathrm{H}_{5} \mathrm{CO}$ & $1.14 \mathrm{e}+13$ & $1.21 \mathrm{e}+14$ \\
\hline $\mathrm{R} 12$ & $\mathrm{CH}_{2} \mathrm{O}+\mathrm{CH}_{3} \mathrm{COCH}_{2}<>\mathrm{RO}$ & $6.25 \mathrm{e}+10$ & $1.23 \mathrm{e}+12$ \\
\hline $\mathrm{R} 13$ & $\mathrm{ROO}<\Rightarrow \mathrm{C}_{2} \mathrm{H}_{3} \mathrm{COCH}_{3}+\mathrm{HO}_{2}$ & $1.80 \mathrm{e}+54$ & $2.23 \mathrm{e}+55$ \\
\hline R14 & $\mathrm{ROO} \Leftrightarrow \mathrm{QOOH}$ & $2.52 \mathrm{e}+12$ & $1.25 \mathrm{e}+13$ \\
\hline R15 & $\mathrm{QOOH} \Leftrightarrow \mathrm{C}_{4} \mathrm{H}_{6} \mathrm{O}_{2}+\mathrm{OH}$ & $7.50 \mathrm{e}+10$ & $1.15 \mathrm{e}+12$ \\
\hline R16 & $\mathrm{QOOH}=>\mathrm{CH}_{2} \mathrm{CO}+\mathrm{OH}+\mathrm{CH}_{3} \mathrm{CHO}$ & $3.10 \mathrm{e}+18$ & $3.97 \mathrm{e}+19$ \\
\hline $\mathrm{R} 17$ & $\mathrm{QOOH}=>\mathrm{CH}_{3} \mathrm{CHCO}+\mathrm{OH}+\mathrm{CH}_{2} \mathrm{O}$ & $1.18 \mathrm{e}+09$ & $2.26 \mathrm{e}+10$ \\
\hline R18 & $\mathrm{C}_{4} \mathrm{H}_{6} \mathrm{O}_{2}+\mathrm{OH}=>\mathrm{H}_{2} \mathrm{O}+\mathrm{HCCO}+\mathrm{CH}_{3} \mathrm{CHO}$ & $2.50 \mathrm{e}+12$ & $3.58 \mathrm{e}+13$ \\
\hline R19 & $\mathrm{C}_{4} \mathrm{H}_{6} \mathrm{O}_{2}+\mathrm{OH} \Rightarrow \mathrm{H}_{2} \mathrm{O}+\mathrm{CH}_{3} \mathrm{CO}+\mathrm{CH}_{2} \mathrm{CO}$ & $2.50 \mathrm{e}+12$ & $5.77 \mathrm{e}+13$ \\
\hline $\mathrm{R} 20$ & $\mathrm{C}_{4} \mathrm{H}_{6} \mathrm{O}_{2}+\mathrm{OH}=>\mathrm{H}_{2} \mathrm{O}+\mathrm{HCO}+\mathrm{C}_{2} \mathrm{H}_{3} \mathrm{CHO}$ & $2.50 \mathrm{e}+12$ & $4.41 \mathrm{e}+13$ \\
\hline \multirow{2}{*}{$\mathrm{R} 21$} & $\mathrm{C}_{2} \mathrm{H}_{3} \mathrm{COCH}_{3}(+\mathrm{M}) \Leftrightarrow \mathrm{C}_{2} \mathrm{H}_{3} \mathrm{CO}+\mathrm{CH}_{3}(+\mathrm{M})$ & $9.77 \mathrm{e}+20$ & $1.09 \mathrm{e}+22$ \\
\hline & Low-pressure limit & $2.34 \mathrm{e}+73$ & $1.87 \mathrm{e}+74$ \\
\hline $\mathrm{R} 22$ & $\mathrm{H}+\mathrm{C}_{2} \mathrm{H}_{3} \mathrm{COCH}_{3} \Leftrightarrow \mathrm{C}_{2} \mathrm{H}_{4}+\mathrm{CH}_{3} \mathrm{CO}$ & $1.03 \mathrm{e}+18$ & $1.37 \mathrm{e}+19$ \\
\hline $\mathrm{R} 23$ & $\mathrm{C}_{2} \mathrm{H}_{3} \mathrm{COCH}_{3}+\mathrm{OH} \Leftrightarrow \mathrm{CH}_{3} \mathrm{CHO}+\mathrm{CH}_{3} \mathrm{CO}$ & $4.12 \mathrm{e}+24$ & $7.43 \mathrm{e}+25$ \\
\hline $\mathrm{R} 24$ & $\mathrm{CH}_{3} \mathrm{CHO}+\mathrm{H} \Leftrightarrow \mathrm{CH}_{3} \mathrm{CO}+\mathrm{H}_{2}$ & $1.31 \mathrm{e}+05$ & $3.14 \mathrm{e}+06$ \\
\hline $\mathrm{R} 25$ & $\mathrm{CH}_{3} \mathrm{CHO}+\mathrm{OH} \Leftrightarrow \mathrm{CH}_{3} \mathrm{CO}+\mathrm{H}_{2} \mathrm{O}$ & $3.37 \mathrm{e}+12$ & $7.04 \mathrm{e}+13$ \\
\hline \multirow{2}{*}{$\mathrm{R} 26$} & $\mathrm{CH}_{3} \mathrm{CHO}(+\mathrm{M})<=\mathrm{CH}_{3}+\mathrm{HCO}(+\mathrm{M})$ & $2.45 \mathrm{e}+22$ & $7.11 \mathrm{e}+23$ \\
\hline & Low -pressure limit & $1.03 \mathrm{e}+59$ & $2.94 \mathrm{e}+60$ \\
\hline \multirow{2}{*}{$\mathrm{R} 27$} & $\mathrm{CH}_{3} \mathrm{CHO}(+\mathrm{M})<\mathrm{CH}_{4}+\mathrm{CO}(+\mathrm{M})$ & $2.72 \mathrm{e}+21$ & $3.21 \mathrm{e}+22$ \\
\hline & Low -pressure limit & $1.14 \mathrm{e}+58$ & $2.43 \mathrm{e}+59$ \\
\hline \multirow{2}{*}{$\mathrm{R} 28$} & $\mathrm{CH}_{3} \mathrm{CO}(+\mathrm{M})<=\mathrm{CH}_{3}+\mathrm{CO}(+\mathrm{M})$ & $1.07 \mathrm{e}+12$ & $2.40 \mathrm{e}+13$ \\
\hline & Low -pressure limit & $5.65 \mathrm{e}+18$ & $7.44 \mathrm{e}+19$ \\
\hline \multirow{2}{*}{$\mathrm{R} 29$} & $\mathrm{CH}_{3} \mathrm{CHCO}(+\mathrm{M})<\mathrm{C}_{2} \mathrm{H}_{4}+\mathrm{CO}(+\mathrm{M})$ & $1.81 \mathrm{e}+10$ & $1.59 \mathrm{e}+13$ \\
\hline & Low -pressure limit & $1.00 \mathrm{e}+54$ & $2.08 \mathrm{e}+56$ \\
\hline $\mathrm{R} 30$ & $\mathrm{CH}_{2} \mathrm{CO}+\mathrm{CH}_{3} \Leftrightarrow \mathrm{CH}_{3} \mathrm{COCH}_{2}$ & $1.76 \mathrm{e}+04$ & $2.70 \mathrm{e}+05$ \\
\hline R31 & $\mathrm{C}_{2} \mathrm{H}_{5}+\mathrm{CO} \Leftrightarrow \mathrm{C}_{2} \mathrm{H}_{5} \mathrm{CO}$ & $1.51 \mathrm{e}+11$ & $1.01 \mathrm{e}+12$ \\
\hline
\end{tabular}




\subsection{Prediction results}

The comparisons between the predicted results using different mechanisms and the experimental data at Cases 1-8 are shown in Fig. 6. As can be seen, the optimized reduced mechanism predicts experimental data well for both the ignition delay times and laminar flame speeds. The optimized reduced mechanism has similar trend with detailed mechanism in all conditions. The detail errors of MAE and MAPE are shown in Table 3. The errors of optimized reduced mechanism are much less than those of the raw-reduced mechanism and even less than the detailed mechanism expect Case 6. It indicates that reduced mechanism optimized by $\mathrm{SaDE}$ algorithm is reliable for the prediction of ignition delay times and laminar flame speeds of 2butanone.

\subsection{Mechanism validation}

Cases 9-11, which are not used for training during optimization process, are employed to validate the reduced mechanism. As shown in Fig. 7, the optimized reduced mechanism also predicts well experimental data,

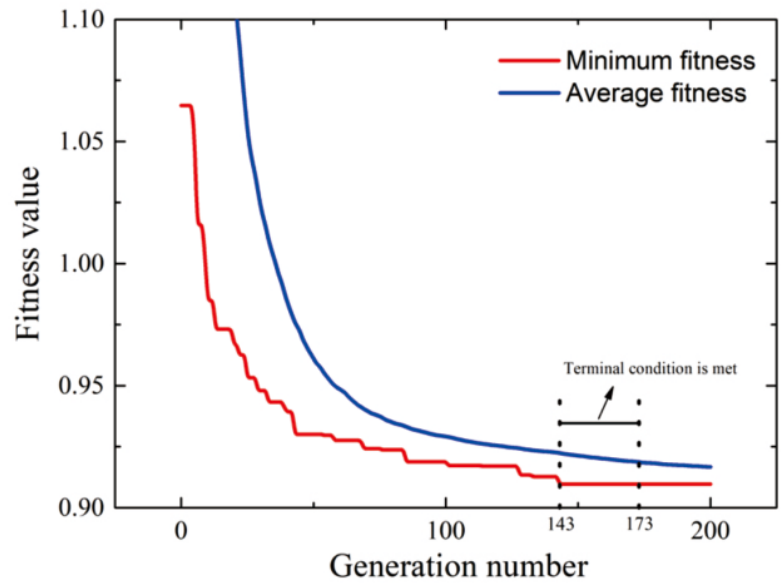

Fig. 5 The evolution of the fitness function.
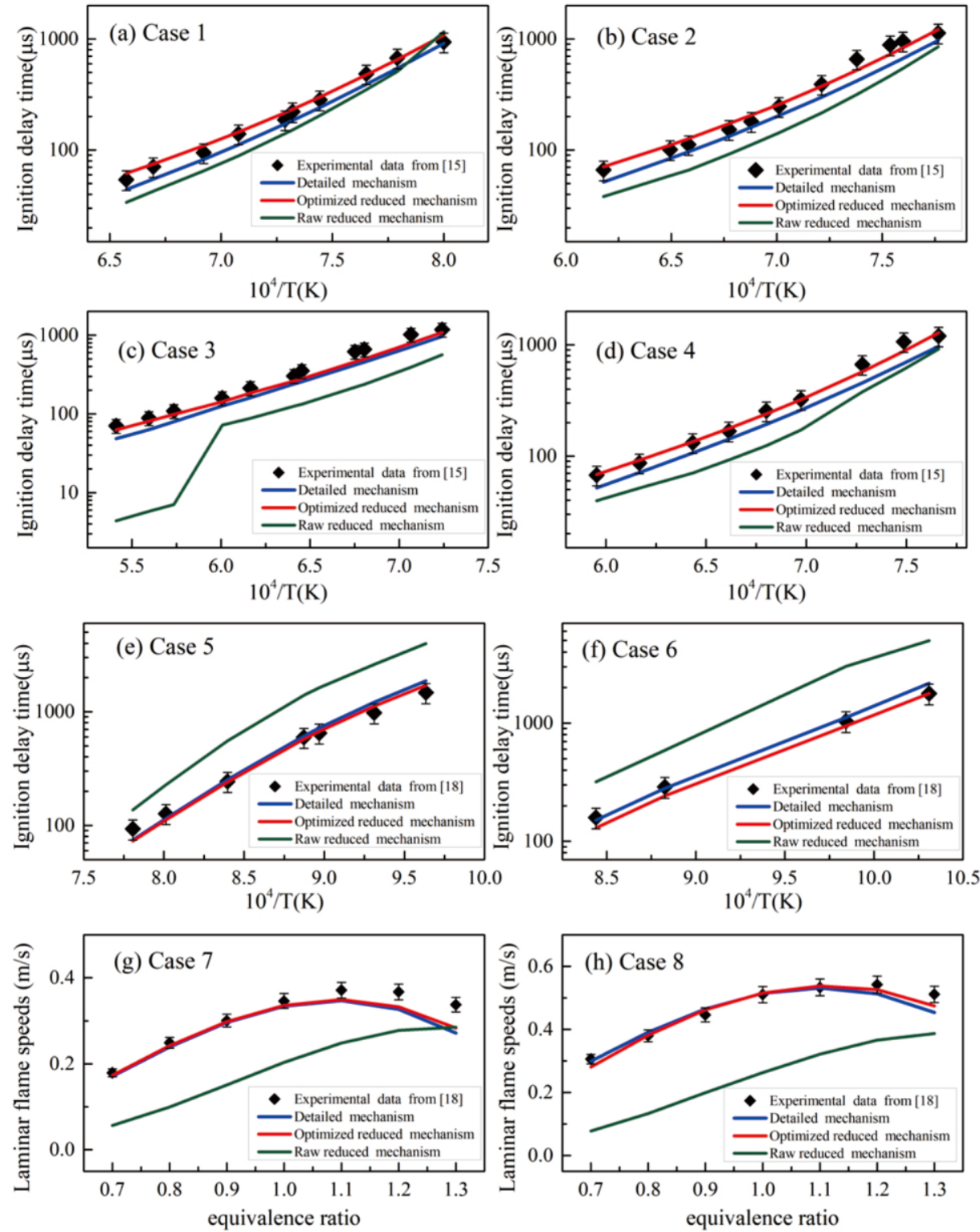

Fig. 6 Comparison between optimized reduced mechanism, raw reduced mechanism and detailed mechanism at Cases 1-8, experimental data are from. ${ }^{12} 15$ 
and has the comparable performance as the detailed mechanism. It indicates that optimized reduced mechanism has stable predictive performance. The detail errors of MAE and MAPE are listed in Table 4. Considering the both good performance of reduced mechanism for training set and test set, it can be conclude that the reduced mechanism optimized by $\mathrm{SaDE}$ is reasonable and believable in prediction at low-tohigh temperatures and different pressures.

\section{Comparison between SaDE and other evolutionary algorithms}

2-butanone reduced mechanism optimization are also conducted using genetic algorithm $(\mathrm{GA})^{51}$ and particle swarm optimization (PSO), respectively. The crossover rates used in GA and particle velocities used in PSO are listed in Table 5. The fitness values during the evolution process of different algorithms are shown in Fig. 8(a). Due to the large CR value of GA_2 and the small velocity of PSO_2, GA_2 and PSO_1 express a better performance than GA_1 and PSO_2, respectively. Overall, $\mathrm{SaDE}$ obtains a smaller fitness value and a faster convergent solution than other algorithms.

The absolute percentage errors of the prediction results of Cases 111 by five reduced mechanisms are shown in Fig. 8(a). Boxplot can

Table 3 Comparison of estimation performance of different mechanism at Cases 1-8.

\begin{tabular}{ccccccc}
\hline \multirow{2}{*}{ Conditions } & \multicolumn{2}{c}{ Detail mechanism } & \multicolumn{2}{c}{$\begin{array}{c}\text { Optimized reduced } \\
\text { mechanism }\end{array}$} & \multicolumn{2}{c}{ Raw-reduced mechanism } \\
\cline { 2 - 7 } & MAE$(\mu \mathrm{s})$ & MAPE $(\%)$ & MAE $(\mu \mathrm{s})$ & MAPE $(\%)$ & MAE $(\mu \mathrm{s})$ & MAPE $(\%)$ \\
\hline Case 1 & 41.18 & 15.46 & 26.72 & 8.78 & 84.23 & 30.46 \\
Case 2 & 110.08 & 21.10 & 54.83 & 11.30 & 179.56 & 41.53 \\
Case 3 & 114.01 & 26.65 & 75.83 & 15.43 & 266.31 & 68.91 \\
Case 4 & 114.94 & 22.94 & 45.75 & 6.71 & 168.59 & 42.45 \\
Case 5 & 107.69 & 13.92 & 31.37 & 5.28 & 909.65 & 125.1 \\
Case 6 & 119.07 & 9.19 & 67.17 & 15.17 & 1413.35 & 143.8 \\
\hline & MAE $(\mathrm{m} / \mathrm{s})$ & MAPE $(\%)$ & MAE $(\mathrm{m} / \mathrm{s})$ & MAPE $(\%)$ & MAE $(\mathrm{m} / \mathrm{s})$ & MAPE $(\%)$ \\
\hline Case 7 & 0.024 & 7.20 & 0.019 & 5.88 & 0.12 & 41.76 \\
Case 8 & 0.018 & 3.85 & 0.015 & 3.46 & 0.21 & 48.59 \\
\hline
\end{tabular}
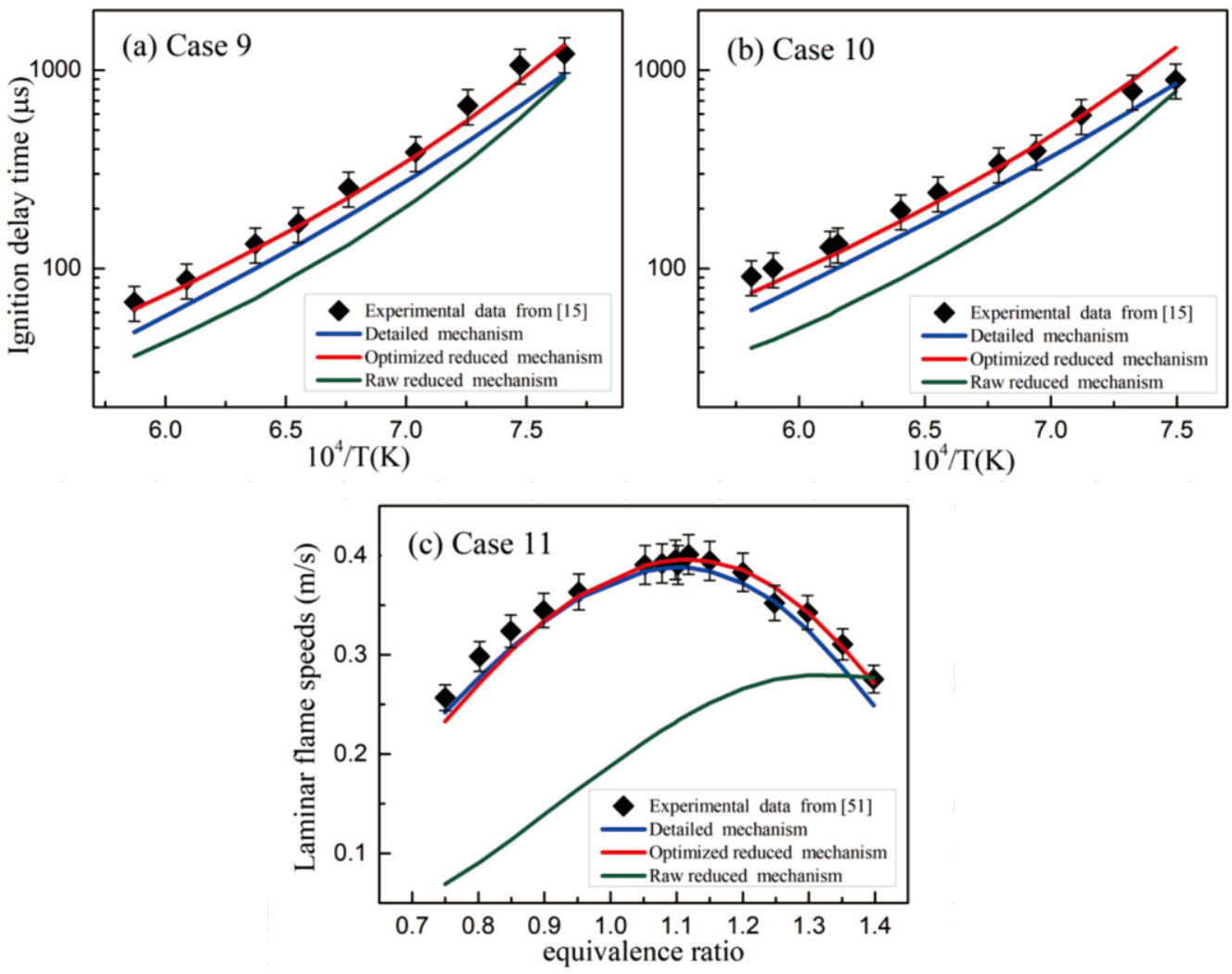

Fig. 7 Comparison between optimized reduced mechanism, raw reduced mechanism and detailed mechanism at Cases 9-11, experimental data are from. ${ }^{12,50}$ 
accurately describe the discrete distribution of data and compare the differences between different groups of data. The small box means that most data are within a small range. As can be seen in fig. 8(a), the mechanism optimized by SaDE has smaller absolute percentage errors in total, which means a more stable performance than other algorithms. Moreover, due to dynamic adjustment of generation strategy and control parameters, SaDE can avoid the time-consuming exhaustive search for the most suitable combination, which make it have better robustness for various problems with different characteristic. It is concluded that $\mathrm{SaDE}$ is more effective and reliable in obtaining best solution for reaction rates adjustment than other algorithms.

\section{Conclusion}

The 2-butanone reduced mechanism containing 50 species and 190 reactions is developed for the first time. Firstly, the raw reduced mechanism is built in three parts, i.e., a reduced $\mathrm{C}_{4}-\mathrm{C}_{\mathrm{n}}$ sub-mechanism, a reduced $\mathrm{C}_{2}-\mathrm{C}_{3}$ sub-mechanism and a detailed $\mathrm{H}_{2} / \mathrm{CO} / \mathrm{C}_{1}$ sub-mechanism. Secondly, the reaction rates of 31 reactions in $\mathrm{C}_{4}-\mathrm{C}_{\mathrm{n}}$ sub-mechanism are optimized by self-adaptive differential evolution algorithm to predict the ignition delay times (Cases 1-6) and flame speeds in constant volume bombs (Cases 7-8). The optimized reduced mechanism is validated by the ignition delay times in shock tubes (Cases 9-10) and laminar flame speeds in constant volume bombs (Case 11). The results of the optimized reduced mechanism are similar to those of the detailed mechanism. Therefore, the reduced mechanism is reliable for the prediction of ignition delay times and laminar flame speeds of 2 butanone.

Mmoreover, the performance of self-adaptive differential evolution algorithm is much better than the genetic algorithm and the particle swarm optimization. The results demonstrate that self-adaptive differential evolution algorithm has faster convergent speed and smaller errors over a wide range of conditions. This work indicates that selfadaptive differential evolution algorithm has better robust performance and it may be a guide for future work to solve various global optimization problems in energy and fuel study.

\section{Acknowledgements}

The work was sponsored by the general program of the National Natural Science Foundation of China No.51776081(C.Z.) and Fundamental Research Funds for the Central Universities No.

Table 4 Comparison of estimation performance of different mechanism at Cases 9-10.

\begin{tabular}{ccccccc}
\hline & \multicolumn{2}{c}{ Detail mechanism } & \multicolumn{2}{c}{$\begin{array}{c}\text { Optimized reduced } \\
\text { mechanism }\end{array}$} & \multicolumn{2}{c}{ Raw-reduced mechanism } \\
\hline & MAE $(\mu \mathrm{s})$ & MAPE $(\%)$ & MAE $(\mu \mathrm{s})$ & MAPE $(\%)$ & MAE $(\mu \mathrm{s})$ & MAPE $(\%)$ \\
\cline { 2 - 7 } Case 9 & 128.55 & 27.36 & 53.08 & 8.92 & 177.65 & 43.66 \\
Case 10 & 65.88 & 21.25 & 59.24 & 13.03 & 146.77 & 44.69 \\
\hline Case 11 & MAE $(\mathrm{m} / \mathrm{s})$ & MAPE $(\%)$ & MAE $(\mathrm{m} / \mathrm{s})$ & $\mathrm{MAPE}(\%)$ & $\mathrm{MAE}(\mathrm{m} / \mathrm{s})$ & $\mathrm{MAPE}(\%)$ \\
\hline
\end{tabular}
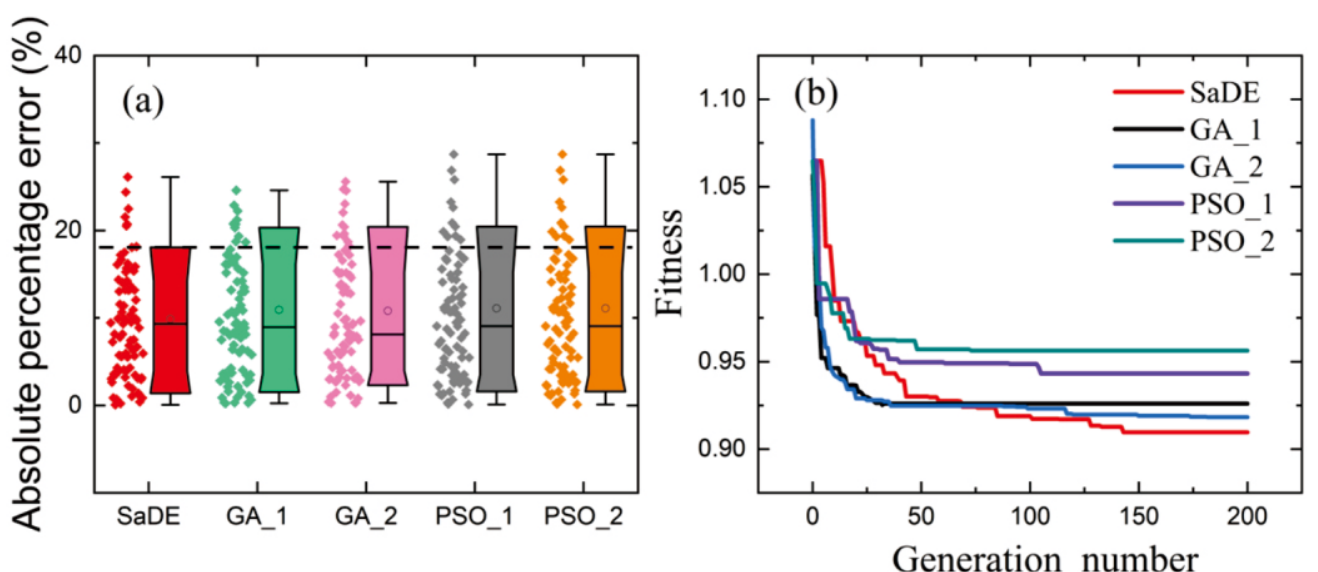

Fig. 8 (a) Boxplot of absolute percentage error of reduced mechanisms optimized by different algorithms. (b) Comparison of fitness value in evolution among different algorithms.

Table 5 Control parameters of different algorithms.

\begin{tabular}{lclc}
\hline Algorithms & Crossover rate & Algorithms & Particle velocity \\
\hline GA_1 & 0.5 & PSO_1 & $0 \sim 1$ \\
GA_2 & 0.9 & PSO_2 & $3 \sim 4$ \\
\hline
\end{tabular}


2019kfyRCPY045 (N.Y.). The authors thank the National Supercomputing Center in Tianjin (NSCC-TJ) and the China Scientific Computing Grid (ScGrid) for assistance in computations.

\section{Supplementary materials}

Mechanism files for Cantera 2.4.0 and Chemkin can be found in supporting information.

\section{References}

1. H. Daly, Appl. Energ., 1994, 47, 101-121.

2. A. K. Gupta, Energ. Convers. Manage., 1997, 38, 1311-1318.

3. S. V. Vassilev, D. Baxter, L. K. Andersen, C. G. Vassileva and T. J. Morgan, Fuel, 2012, 94, 1-33.

4. Y. Li, W. Tang, Y. Chen, J. Liu and C. F. Lee, Fuel, 2019, 242, 673-686.

5. J. L. Stephen and B. Periyasamy, Fuel, 2018, 214, 623-633.

6. J. Mo, C. Tang, J. Li, L. Guan and Z. Huang, Fuel, 2016, 182, 391-401.

7. S. Y. No, Fuel, 2016, 183, 641-658.

8. E. Hu, Z. Xu, Z. Gao, J. Xu and Z. Huang, Fuel, 2019, 256, 115933.

9. F. Hoppe, U. Burke, M. Thewes, A. Heufer, F. Kremer and S. Pischinger, Fuel, 2016, 167, 106-117.

10. C. Schulz and V. Sick, Prog. Energ. Combust., 2005, 31, 75-121.

11. V. Decottignies, L. Gasnot and J. F. Pauwels, Combust. Flame, 2002, 130, 225-240.

12. Z. Serinyel, G. Black, H. J. Curran and J. M. Simmie, Combust. Sci. Technol., 2010, 182, 574-587.

13. Z. Serinyel, N. Chaumeix, G. Black, J. M. Simmie and H. J. Curran, J. Phys. Chem. A, 2010, 114, 12176-12186.

14. Badra, Elwardany, E. Ahmed, Khaled, Fethi, Vasu, et al., Combust. Flame, 2014, 161, 725-734.

15. U. Burke, J. Beeckmann, W. A. Kopp, Y. Uygun, H. Olivier, L. Kai, et al., Combust. Flame, 2016, 168, 296-309.

16. C. Hemken, U. Burke, K. Y. Lam, D. F. Davidson, R. K. Hanson, K. A. Heufer, et al., Combust. Flame, 2017, 184, 195-207.

17. T. Lu and C. K. Law, P. Combust. Inst., 2005, 30, 1333-1341.

18. X. You, F. N. Egolfopoulos and H. Wang, P. Combust. Inst., 2009, 32, 403410.

19. H. Huang, J. Zhu, Z. Zhu, H. Wei, D. Lv, P. Zhang, et al., Energ. Convers. Manage., 2017, 149, 553-563.

20. H. An, W. M. Yang, A. Maghbouli, J. Li and K. J. Chua, Energ. Convers. Manage., 2014, 81, 51-59.

21. S. S. Ahmed, F. Mauß, G. Moréac and T. Zeuch, Phys. Chem. Chem. Phys., 2007, 9, 1107-1126

22. C. K. Westbrook, W. J. Pitz, J. E. Boercker, H. J. Curran, J. F. Griffiths, C. Mohamed, et al., P. Combust. Inst., 2002, 29, 1311-1318.

23. L. Cai, H. Pitsch, S. Y. Mohamed, V. Raman, J. Bugler, H. Curran, et al., Combust. Flame, 2016, 173, 468-482.

24. Z. Gao, X. Zou, Z. Huang and L. Zhu, Fuel, 2019, 242, 438-446.

25. A. Baghban and M. Adelizadeh, Fuel, 2018, 230, 344-354.
26. R. Ma, D. Huang, T. Zhang and T. Luo, Chem. Phys. Lett., 2018, 704, 49-54.

27. X. Wan, W. Feng, Y. Wang, H. Wang, X. Zhang, C. Deng, et al., Nano Lett., 2019, 19, 3387-3395

28. R. Ma, Z. Liu, Q. Zhang, Z. Liu and T. Luo, J. Chem. Inf. Model., 2019, 59, 3110-3119.

29. S. Ju, T. Shiga, L. Feng, Z. Hou, K. Tsuda and J. Shiomi, Phys. Rev. X, 2017, 7, 021024.

30. D. Ma, A. Arora, S. Deng, G. Xie, J. Shiomi and N. Yang, Materials Today Physics, 2019, 8, 56-61.

31. T. Liu, J. E, W. M. Yang, Y. Deng, H. An, Z. Zhang, et al., Energy, 2018, 150, 1031-1038

32. Y. Chang, J. Ming, N. Bo, X. Zhen, Z. Liu, Y. Li, et al., Combust. Flame, 2018, 194, 15-27.

33. D. A. Sheen, X. You, H. Wang and T. Løvås, P. Combust. Inst., 2009, 32, $535-542$

34. A. K. Qin, V. L. Huang and P. N. Suganthan, IEEE T. Evolut. Comput., 2009, 13, 398-417.

35. Y. Chang, M. Jia, J. Xiao, Y. Li, W. Fan and M. Xie, Energ. Convers. Manage., 2016, 128, 250-260.

36. K. V. Price, Handbook of Optimization, Springer2013. pp. 187-214.

37. R. Storn and K. Price, J. Global Optim., 1997, 11, 341-359.

38. Goodwin David G, Harry K. Moffat, and Bryan W. Weber, https://www.cantera.org, 2016.

39. J. Jayachandran, R. Zhao and F. N. Egolfopoulos, Combust. Flame, 2014 161, 2305-2316

40. G. R. Harik, F. G. Lobo and D. E. Goldberg, The compact genetic algorithm, 1999, 3, 287-297.

41. R. Eberhart and J. Kennedy, MHS'95 Proceedings of the Sixth International Symposium on Micro Machine and Human Science, 1995, pp, 39-43.

42. D. Whitley, Stat. Comput., 1994, 4, 65-85.

43. Eberhart and S. Yuhui, Proceedings of the 2001 Congress on Evolutionary Computation (IEEE Cat No01TH8546), 2001, 1, 81-86.

44. Q. Lin, K. L. Tay, D. Zhou and W. Yang, Energ. Convers. Manage., 2019, 185, 35-43

45. B. Mohan, K. L. Tay, W. Yang and K. J. Chua, Energ. Convers. Manage., 2015, 105, 1223-1238

46. Y. Chang, M. Jia, Y. Li, Y. Liu, M. Xie, H. Wang, et al., Combust. Flame, 2015, 162, 3785-3802.

47. C. Hemken, U. Burke, K. Y. Lam, D. F. Davidson, R. K. Hanson, K. A. Heufer, et al., Combust. Flame, 2017, 184, 195-207.

48. U. Burke, K. P. Somers, P. O'Toole, C. M. Zinner, N. Marquet, G. Bourque, et al., Combust. Flame, 2015, 162, 315-330.

49. U. Burke, W. K. Metcalfe, S. M. Burke, K. A. Heufer, P. Dagaut and H. J. Curran, Combust. Flame, 2016, 165, 125-136.

50. Z. Serinyel, N. Chaumeix, G. Black, J. M. Simmie and H. J. Curran, J. Phys. Chem. A, 2010, 114, 12176-12186.

51. J. H. Holland, Adaptation in Natural and Artificial System1992.

Publisher's Note Engineered Science Publisher remains neutral with regard to jurisdictional claims in published maps and institutional affiliations. 